\title{
Phenotypic Alteration of Astrocytes Induced by Ciliary Neurotrophic Factor in the Intact Adult Brain, As Revealed by Adenovirus-Mediated Gene Transfer
}

\author{
Fabrice Lisovoski, ${ }^{1}$ Said Akli, ${ }^{2}$ Elise Peltekian, ${ }^{1}$ Emmanuelle Vigne, ${ }^{3}$ Georg Haase, ${ }^{2}$ Michel Perricaudet, ${ }^{3}$ \\ Patrick A. Dreyfus, ${ }^{1}$ Axel Kahn, ${ }^{2}$ and Marc Peschanski ${ }^{1}$ \\ ${ }^{1}$ Faculté de Médecine, Institut National de la Santé et de la Recherche Médicale Unité 421, Institut Mondor de Médecine \\ Moléculaire, Institut Gustave Roussy, 94010 Créteil Cedex, France, 2Institut National de la Santé et de la Recherche \\ Médicale Unité 129, Institut Cochin de Genetique Moleculaire, 75014 Paris, France, and ${ }^{3}$ Centre National de la \\ Recherche Scientifique, Unité de Recherche Associée 1301/Rhône-Poulenc Rorer, Institut Mondor de Médecine \\ Moléculaire, Institut Gustave Roussy, 94805 Villejuif Cedex, France
}

Synthesis of the ciliary neurotrophic factor (CNTF) and its specific receptor (CNTFR $\alpha$ ) is widespread in the intact CNS, but potential biological roles for this system remain elusive. Contradictory results have been obtained concerning a possible effect on the morphological and biochemical phenotype of astrocytes. To reassess this question, we have taken advantage of adenovirus-mediated gene transfer into the rat brain to obtain the local release of CNTF. Stereotaxic administration of CNTF recombinant adenovirus vectors into the striatum led to phenotypic changes in astrocytes located in regions that were related axonally to striatal neurons at the injection site. Astrocytes appeared hypertrophied and displayed an increase in both GFAP and CNTF immunoreactivity. This response was observed up to 5 weeks after injection, the longest time studied. It was not observed after the administration of a control vector. The methodology used in the present study, allowing us to analyze the effect of the factor in areas remote from the injection site, has provided conclusive evidence that CNTF affects the astroglial phenotype in the intact CNS. The characteristics of these effects may explain why contradictory results have been obtained previously, because this signaling system seems to have a low efficiency and therefore requires a high local concentration of the factor close to the target cells. One might speculate as to the involvement of a CNTF astroglioastroglial signaling system in the organized response of a population of astrocytes to changes in CNS homeostasis detected locally, even by a single cell.

Key words: CNTF; adenovirus vector; astroglial differentiation; in vivo gene transfer; astrogliosis
The biological roles of the ciliary neurotrophic factor (CNTF) in the CNS remain a matter of speculation. There is a large body of data demonstrating that $\mathrm{CNTF}$ and its specific receptor, CNTFR $\alpha$, are synthesized by numerous cells in the CNS (see references in Richardson, 1994; Sendtner et al., 1994; Stahl and Yancopoulos, 1994; Mac Lennan et al., 1996), suggesting that CNTF may play important roles therein. Application of exogenous CNTF to various neural cell populations has profound effects. Raff and colleagues have demonstrated a differentiating effect on glial progenitors, directing their maturation toward an astrocytic phenotype (Hughes et al., 1988). There does not seem to be, however, a significant synthesis of CNTF during development (Stöckli et al., 1989). A protective effect of CNTF on various neuronal and glial populations also has been established (Louis et al., 1993; Richardson et al., 1994; Sendtner et al., 1994; Sagot et al., 1995; Anderson et al., 1996; Emerich et al., 1996).

Received March 26, 1997; revised June 12, 1997; accepted July 10, 1997

This study was supported by grants from Institut National de la Santé et de la Recherche Médicale and Association Française contre les Myopathies. We are greatly indebted to Drs. P. Greengard, M. Sendtner, and H. Thoenen for providing antibodies and plasmids. We also thank C. Gable and C. Bouchard, who participated in preliminary experiments, and Dr. E. Parrish for review of this manuscript.

Correspondence should be addressed to Dr. Marc Peschanski, Faculté de Médecine, Institut National de la Santé et de la Recherche Médicale Unité 421, IM3, Faculté de Médecine, 94010 Créteil Cedex, France.

Copyright (C) 1997 Society for Neuroscience $0270-6474 / 97 / 177228-09 \$ 05.00 / 0$
Exogenous CNTF is able to rescue motoneurons and thalamic, septal, and striatal neurons as well as oligodendrocytes.

These results have led to the hypothesis that CNTF may act specifically as an "injury molecule" in the adult CNS, with a protective role (Thoenen, 1991; Adler, 1993). Such an hypothesis is, however, difficult to reconcile with the widespread synthesis of CNTF and CNTFR $\alpha$ in the intact adult CNS. This hypothesis was based, also, on the fact that CNTF lacks a signal peptide and cannot, therefore, be secreted via a conventional pathway, suggesting that only cell damage could lead to its release. It is known, however, that other molecules lacking a signal peptide, e.g., the 18 $\mathrm{kDa}$ isoform of basic fibroblast growth factor (bFGF) and interleukin (IL)-1 $\beta$, are secreted via a nonconventional energydependent pathway (Rubartelli et al., 1990; Florkiewicz et al., 1995). In addition, the low abundance of CNTF in the medium of astrocytic cultures (Lillien et al., 1988) may be attributable, at least in part, to the trapping of released CNTF molecules by membrane-bound receptors (Kamiguchi et al., 1995). Neuroprotection during CNS damage therefore may not summarize entirely the biological role of CNTF.

Recent experiments have approached this issue by injecting recombinant CNTF into the otherwise intact adult CNS (Winter et al., 1995; Clatterbuck et al., 1996; Levison et al., 1996). These injections have induced morphological and biochemical astroglial differentiation (or so-called "activation"). Although these authors took good care in comparing these data with the appropriate 
controls, it is difficult to avoid lesioning CNS tissue during intracerebral injections; this in itself induces reactive gliosis. In addition, it has not been possible to replicate these findings in other in vivo experiments (Emerich et al., 1996) nor in astrocytic cultures (Smith et al., 1996); thus, the issue remains controversial.

The present study has been undertaken to address this issue of a differentiating effect of CNTF on astroglia in the intact adult CNS, using a methodology that would create as little harm as possible and taking advantage of the ability of adenovirus vectors to transfer a gene into neural cells in vivo.

\section{MATERIALS AND METHODS}

The effects of the intracerebral administration of two adenoviral vectors recombinant for the lacZ gene of Escherichia coli (AdRSV.nlslacZ; Stratford-Perricaudet et al., 1990) and for a gene construct encoding a secreted form of CNTF, respectively, were studied in adult Sprague Dawley rats.

Preparation of viral vectors. Digestion of the plasmid pChim5, generously provided by Drs. Sendtner and Thoenen (Sendtner et al., 1992), by $H i n$ dIII and $X b a I$ leaves a DNA fragment containing the rat genomic DNA (exon 1, intron, exon 2) and an attached sequence encoding the mouse NGF signal peptide. After the ends were filled with the Klenow fragment of DNA polymerase I, the DNA was ligated into the adenoviral plasmid digested by EcoRV downstream of the Rous sarcoma virus (RSV) long terminal repeat, according to a previously described technique (Stratford-Perricaudet et al., 1990). This gave rise to a plasmid, pAdRSV.CNTF, which was used for homologous recombination with the Ad1327 mutant virus deleted in regions $\mathrm{E}_{1} \mathrm{~A}, \mathrm{E}_{1} \mathrm{~B}$, and $\mathrm{E}_{3}$ (see Fig. $1 A$ ). After isolation, the virus vector AdRSV.CNTF was amplified in 293 cells, a transcomplementing cell line for $\mathrm{E}_{1}$ function (Graham et al., 1977), and obtained at titers up to $10^{12} \mathrm{pfu} / \mathrm{ml}$.

In vitro experiments. Cultures of purified motoneuronal populations were prepared according to Bloch-Gallego et al. (1991). The spinal cord of leghorn chicken embryos at 5.5 d (Hamburger-Hamilton stage 27-28) was dissected out, treated with trypsin, and then mechanically dissociated. Cells were placed for $1 \mathrm{hr}$ at $37^{\circ} \mathrm{C}$ in a Petri dish coated with SC1 antibodies. After being rinsed, motoneurons were eluted with an excess of SC1 antibodies and seeded in polyornithine-coated Petri dishes (35 $\mathrm{mm}$ in diameter) so that the number of cells per dish corresponded, approximately, to one half spinal cord. Cells were cultured in Ham's $\mathrm{F}_{12}$ medium supplemented with insulin $(10 \mu \mathrm{g} / \mathrm{ml})$ and glucose $(10 \mathrm{~mm})$. Survival of motoneurons was analyzed in parallel, using four types of experimental procedures: (1) without complementation; (2) with a complement of chick muscle extract, prepared as described by Henderson et al. (1993); (3) with infection using AdRSV.nlslacZ $\left(10^{7} \mathrm{pfu} / \mathrm{ml}\right)$ for $1 \mathrm{hr}$, $24 \mathrm{hr}$ after the beginning of the session; (4) with a similar protocol of infection using AdRSV.CNTF. The number of surviving neurons was counted every other day with a phase-contrast microscope. In addition, the morphology of neurons treated with AdRSV.CNTF was analyzed after 4, 6, and $8 \mathrm{~d}$ in culture. In this latter case, motoneurons were infected with both AdRSV.CNTF and AdRSV.nlsLacZ for better viewing of their structure. Cells were fixed by treatment with $4 \%$ paraformaldehyde in phosphate buffer, $\mathrm{pH} 7.4(0.1 \mathrm{M})$.

CNTF protein measurement. CNTF protein levels were measured in triplicate samples by a two-site enzyme immunoassay, according to the manufacturer's protocol, using monoclonal anti-CNTF antibodies (clone 5/3/6B and clone 4-68; Boehringer Mannheim, Mannheim, Germany) that recognize rat $\mathrm{CNTF}$.

A 96-well microtiter plate (ELISA plate, Nunc, France) was incubated with $100 \mu \mathrm{l} /$ well of $50 \mathrm{~mm} \mathrm{Na}_{2} \mathrm{CO}_{3} / \mathrm{NaCHO}_{3}$ buffer, $\mathrm{pH} 9.6$, containing $2.5 \mu \mathrm{g} / \mathrm{ml}$ of mouse monoclonal anti-CNTF (clone 5/3/6B) for $3 \mathrm{hr}$ at room temperature (RT). After it was washed with PBS containing $0.1 \%$ Tween 20, each well was incubated for $2 \mathrm{hr}$ at RT with $200 \mu \mathrm{l}$ of $5 \%$ BSA in PBS. Then the wells were incubated for $3 \mathrm{hr}$ at RT with $100 \mu \mathrm{l}$ of the sample or with the standard solution $(0-3 \mathrm{ng} / \mathrm{ml}$ of rat CNTF in PBS containing $1 \%$ BSA and $0.1 \%$ Tween $20, \mathrm{pH} 7.4$; sample buffer). Mouse monoclonal anti-CNTF (clone 4-68) was diluted to $250 \mathrm{mU} / \mathrm{ml}$ with sample buffer. After washing, each well was incubated with $100 \mu \mathrm{l}$ of this solution overnight at $4^{\circ} \mathrm{C}$. After washing, $\beta$-galactosidase activity was determined by incubation with $100 \mu \mathrm{l}$ of the substrate solution $[2 \mathrm{mg} / \mathrm{ml}$ of chlorophenol- $\beta$-galactopyranoside in the substrate buffer containing (in mM): $\mathrm{HEPES} \mathrm{100,} \mathrm{NaCl} 150, \mathrm{MgCl}_{2} 2, \mathrm{BSA} 1 \%, \mathrm{pH} 7.0$ ] for $3 \mathrm{hr}$ in the dark at $37^{\circ} \mathrm{C}$. The optical density of the colored product was mea- sured at $570 \mathrm{~nm}$, using an ELISA reader (Multiscan, Lab System). The detection limit of this assay was evaluated at $95 \mathrm{pg} / \mathrm{ml}$.

For this analysis a population of cells not belonging to the nervous system (rat pleural mesothelial cells) was chosen to avoid possible bias introduced by endogenous synthesis of either CNTF or CNTFR $\alpha$. These cells were kindly provided by Dr. Jaurand (Institut National de la Santé et de la Recherche Médicale U139, Créteil, France) and were cultured in a medium containing penicillin $(10 \mathrm{U} / \mathrm{ml})$, as previously described (Jaurand et al., 1981). When the cells were confluent $\left(3.10^{6}\right.$ cells $/ 25 \mathrm{~cm}^{2}$ ), they were transduced with AdRSV.CNTF ( $80 \mathrm{pfu} /$ cell) in a medium without fetal bovine serum (FBS) for $2 \mathrm{hr}$ at $37^{\circ} \mathrm{C}$. Then the medium was replaced by culture medium containing $10 \%$ FBS.

At $48 \mathrm{hr}$ later the culture medium was changed; the supernatant conditioned during the following $48 \mathrm{hr}$ was collected, and proteins were concentrated (Centrex UF2, Schleicher \& Schuell, Germany) for immunoassay.

In vivo experiments. Intraventricular and intraparenchymal injections of adenovirus vectors were performed in anesthetized adult female Sprague Dawley rats, using stereotaxic coordinates. Intrastriatal (IS) and intracerebroventricular (ICV) injections were performed either with AdRSV.CNTF diluted from a stock solution at a titer of $10^{12} \mathrm{pfu} / \mathrm{ml}$ (IS, $2 \times 10^{7} \mathrm{pfu} / 2 \mu \mathrm{l}$ at 3 points, $n=24$; ICV, $\left.4 \times 10^{9} \mathrm{pfu} / 4 \mu \mathrm{l}, n=4\right)$ or with AdRSV.nlsLacZ (IS, $10^{7}$ at a single point or $2 \times 10^{7} \mathrm{pfu} / 2 \mu \mathrm{l}$ at 3 points, $n=15$; ICV, $\left.4 \times 10^{9} \mathrm{pfu} / 4 \mu \mathrm{l}, n=2\right)$.

In some experiments $(n=6)$ colchicine $(50 \mu \mathrm{g}$ in $10 \mu \mathrm{l})$ was injected intracerebroventricularly $12 \mathrm{hr}$ after intrastriatal injection of AdRSV.CNTF, and the animals were perfused $48 \mathrm{hr}$ later. In other control experiments $(n=4)$ quinolinic acid ( $240 \mathrm{~nm}$; Sigma, France) or $\mathrm{MPP}^{+}(100 \mathrm{~nm}$; Sigma) was injected into the striatum of previously untreated rats. The animals were perfused $8 \mathrm{~d}$ later.

Histological procedures. For in situ hybridization, rats were injected into the right lateral ventricle with AdRSV.CNTF or AdRSV.lacZ. Animals were killed $2 \mathrm{~d}$ later by transcardial perfusion of $4 \%$ paraformaldehyde in $0.1 \mathrm{M}$ phosphate buffer; brains were removed and cryoprotected overnight in a $30 \%$ sucrose phosphate buffer solution. Sections 20 $\mu \mathrm{m}$ thick were cut on a cryostat. Hybridization was performed with $\alpha^{33} \mathrm{P}-\mathrm{CTP}$-labeled sense and antisense RNA probes synthesized by in vitro transcription, using T7 and SP6 RNA polymerase and plasmid vectors pChim5, linearized with NheI, and pRc.CNTF, linearized with HindIII, respectively. These probes span 60 nucleotides (nt) of mouse NGF signal sequence and the initial $70 \mathrm{nt}$ of rat CNTF exon 1. Slides were dipped into nuclear emulsion (Amersham, Les Ulis, France) and revealed after 3 weeks.

For immunocytochemistry, rats were injected either into the lateral ventricle or into the striatum with AdRSV.CNTF or AdRSV.nlslacZ. After various survival times between $24 \mathrm{hr}$ and 5 weeks, animals were killed as described above. Serial coronal sections of the brain were cut at $40 \mu \mathrm{m}$, and adjacent sections were incubated overnight with primary antibodies. Immunostaining was revealed by appropriate biotinylated secondary antibodies (1:200), anti-rabbit or anti-mouse, depending on the primary antibody, and then by the avidin peroxidase technique (Vector, France). Primary antibodies used identified GFAP (rabbit polyclonal, Dako, France), CNTF (mouse monoclonal, generously given by Dr. Sendtner, University of Würzburg, Germany, or from Boehringer Mannheim), DARPP32 (mouse monoclonal, generously provided by Dr. Greengard, The Rockefeller University, New York, NY), the receptor of the third complement fraction (OX-42, mouse monoclonal, Cambridge Research Biochemicals, UK), major histocompatibility complex antigens I and II (OX-18 and OX-6, mouse monoclonals; Cambridge Research Biochemicals), and lymphocytes (OX-19, mouse monoclonal; Cambridge Research Biochemicals). In addition, X-gal histochemistry was used to demonstrate transgene expression after injection of Ad.RSVnlslacZ, according to a previously described technique (Akli et al., 1993).

\section{RESULTS}

Preliminary experiments demonstrated the ability of the AdRVS.CNTF to transfer into neural cells a gene encoding a secreted molecule with biological similarity to $\mathrm{CNTF}$. In vivo studies demonstrated that expression of this transgene provoked morphological and biochemical differentiation of astrocytes in the intact adult rat brain. 


\section{Validation of the AdRSV.CNTF vector}

The ability of the AdRSV.CNTF vector to transduce neural cells and to induce the synthesis of a protein with a biological activity comparable to that of $\mathrm{CNTF}$ was checked in vitro and in vivo.

Northern blot analysis of 293 cells infected with AdRSV.CNTF and harvested for RNA extraction $2 \mathrm{~d}$ later showed two transcripts hybridizing with a CNTF probe (Fig. $1 B$ ). The size of these transcripts corresponded to those expected from the use of two polyadenylation sites present in the $3^{\prime}$ untranslated region of the pIX adenoviral protein contained in the construct.

The amount of CNTF released by control and AdRSV.CNTFtreated mesothelial cells was examined by two-site ELISA. Control supernatants contained no detectable CNTF. CNTF production by transduced mesothelial cells was $54 \mathrm{pg} / 10^{6}$ cells per hour.

Intracerebroventricular injections of $10^{8} \mathrm{pfu}$ of the AdRSV.CNTF vector transduced ependymal cells that transcribed the CNTF gene, as revealed by in situ hybridization, using an antisense probe hybridizing with a fragment encompassing part of both the sequence encoding the signal peptide of NGF and the first exon of CNTF (Fig. 1C). Using the same probe, we found no CNTF transcripts in ependymal cells after intracerebroventricular injection of AdRSV.nlslacZ (Fig. 1C). A positive signal was observed, however, widespread through the parenchyma under both conditions (i.e., after administration of both AdRSV.nlslacZ and AdRSV.CNTF), suggesting that the probe hybridized also with endogenous CNTF transcripts and was not, therefore, specific to the transgene mRNA. Immunohistochemistry with an antibody specifically raised against CNTF revealed the presence of the protein in the same ependymal cell population (Fig. $1 D$ ). No immunostaining was seen in the neighboring parenchyma. Adjacent sections treated to reveal GFAP immunostaining showed no phenotypic changes in astroglia. Intracerebroventricular injections of similar amounts of the control vector, AdRSV.nlslacZ, provoked neither CNTF gene transcription nor CNTF protein synthesis.

A CNTF-like neuroprotective effect of the protein synthesized by transduced cells was sought with an in vitro bioassay by infecting purified populations of chick motoneurons at $5.5 \mathrm{~d}$ and analyzing the survival of cells in Ham's $F_{12}$ medium supplemented with insulin and glucose only (Fig. $1 E$ ). Motoneurons were unable to survive for $4 \mathrm{~d}$ in this medium, untreated or after transduction with AdRSV.nlslacZ. In contrast, they survived up to $9 \mathrm{~d}$ when treated with AdRSV.CNTF, i.e., for as long as when treated with chick muscle extracts. Cultured motoneurons treated with AdRSV.CNTF, fixed after up to $7 \mathrm{~d}$ in culture, displayed a well preserved morphology with a large cell body and long neurites that gave rise to arborizations of secondary branches (Fig. $1 F$ ).

\section{Intraparenchymal injection of adenoviral vectors into the intact brain}

Morphological and biochemical changes in neural cells were sought, using immunohistochemistry, after injection of AdRSV.CNTF into the striatum of adult rats. When amounts as high as $6.10^{7} \mathrm{pfu}$ were injected, little, if any, pathogenicity for surrounding neurons resulted, as judged in Nissl-stained sections (Fig. 2A) and with DARPP32 antibodies. In preliminary experiments, results obtained with higher titers of the AdRSV.CNTF vector showed some neuronal loss around the needle track and were discarded.

A battery of antibodies was used to search for phenotypic alteration of microglia $(\mathrm{OX}-42)$ for the appearance of major histocompatibility complex antigens (OX-6 and OX-18) that are associated with their activation and for the recruitment of lymphocytes (OX-19). All results were negative, except in the discrete area of the needle track in which reactive microglia were immunostained.

In sharp contrast, as early as $24 \mathrm{hr}$ and as late as 5 weeks (latest time studied) after injection of AdRSV.CNTF, a major increase in GFAP immunostaining was visible in the striatum (Fig. $2 B$ ). The area displaying a high level of immunoreactivity encompassed at least the dorsal third of the striatum and, in some cases, its entire width in sections up to $2 \mathrm{~mm}$ away from the injection site revealed by the needle track. This increase in GFAP immunostaining was related to morphological changes in astrocytes, which displayed a larger cell body and hypertrophied processes (Figs. 2B, inset; 3). Over the days after the injection of AdRSV.CNTF, similar signs of astroglial phenotypic changes appeared in other brain nuclei on the side of the injection, namely the globus pallidus (Fig. $2 C, D$ ), the entopeduncular nucleus, the reticularis thalami, medial and intralaminar thalamic nuclei, and the substantia nigra, both in its pars reticulata and in its pars compacta (Fig. $2 E, F$ ).

Control experiments were performed by the injection of AdRSV.nlslacZ. In this case, a cytopathogenicity for neurons surrounding the needle track was visible for injections over $10^{7}$ $\mathrm{pfu}$. Injections of $10^{7} \mathrm{pfu}$ into the striatum transduced cells, as demonstrated by X-gal staining, around the injection site. X-gal-stained neurons also were observed in the ipsilateral cerebral cortex, medial thalamus, substantia nigra pars reticulata (but not in the pars reticulata), and the dorsal raphe. These injections provoked an astroglial response, characterized by an increased GFAP immunoreactivity and morphological changes, in a striatal area in the vicinity of the injection site. In contrast, no astroglial phenotypic alteration was observed in other brain nuclei, including those in which intrastriatal injection of AdRSV.CNTF provoked astroglial phenotypic alteration. Injection of $6.10^{7} \mathrm{pfu}$ of AdRSV.nlslacZ provoked neuronal cell loss in the striatum. Hypertrophied astrocytes with increased GFAP immunoreactivity in these cases were present all along the border of the lesion, and the striatal area containing hypertrophied astrocytes was enlarged, although encompassing no more than a cylinder a few hundred micrometers in width around the lesion site. Under these conditions, astrogliosis also was observed in medial and intralaminar thalamic nuclei and in the substantia nigra in its pars compacta only. Similar results were obtained when a striatal lesion was produced by injection of toxic agents (quinolinic acid or $\mathrm{MPP}^{+}$).

\section{CNTF immunoreactivity after intraparenchymal injection of AdRSV.CNTF}

After intrastriatal injections of AdRSV.CNTF, immunostaining with antibodies specifically raised against CNTF revealed a small area of dense immunoreactivity from 200 to $400 \mu \mathrm{m}$ in diameter around the needle track. Surrounding this area there was also a conspicuous increased immunostaining in an area that was superimposable with that demonstrating increased GFAP immunoreactivity in adjacent sections (Fig. $4 A$ ). In this area surrounding the injection site CNTF-immunoreactive cells were morphologically similar to the GFAP-immunoreactive astrocytes (Fig. 4B). An increased CNTF immunolabeling also was observed outside the striatum in areas superimposable with those displaying increased GFAP immunostaining, including the globus pallidus, entopeduncular nucleus, reticularis thalami, medial and in- 

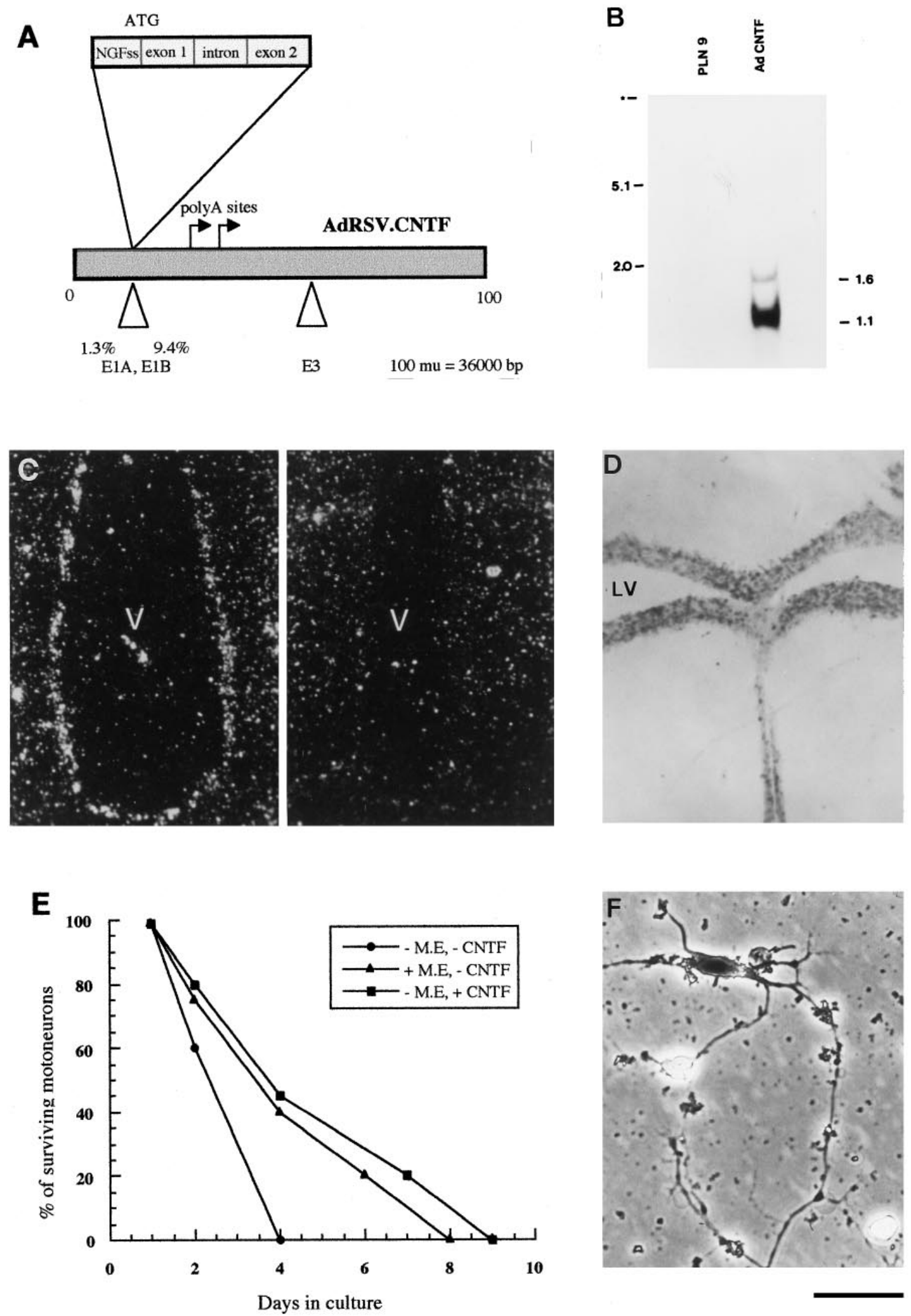

Figure 1. Construction of the CNTF adenovirus vector, and validation. $A$, Construction of the recombinant adenovirus vector using the pChim5 plasmid (Sendtner et al., 1992). B, Northern blot showing the two transcripts of 1.1 and $1.6 \mathrm{kbp}$, respectively, present at a ratio of 9:1 in 293 cell preparations infected with AdRSV.CNTF (right), but not in controls (nonrecombinant PLN9 adenovirus, left). A CNTF genomic probe was used to identify the transcripts. $C$, In situ hybridization of ependymal cells of the third ventricle $(V)$ after intraventricular injection of AdRSV.CNTF (left) or AdRSV.nlsLacZ (right). D, CNTF immunohistochemistry showing ependymal cells of the lateral ventricles $(L V)$ immunostained for CNTF after intracerebroventricular injection of AdRSV.CNTF. E, Survival of purified motoneuronal populations in Ham's $\mathrm{F}_{12}$ medium, treated with muscle extract (M.E.) or AdRSV.CNTF. All surviving neurons were counted in a representative experiment in six to nine Petri dishes at various times after plating. $F$, Morphology of a cultured motoneuron $7 \mathrm{~d}$ after infection with AdRSV.CNTF. Scale bar (at bottom right): $160 \mu \mathrm{m}$ in $C ; 400 \mu \mathrm{m}$ in $D ; 35 \mu \mathrm{m}$ in $F$. 

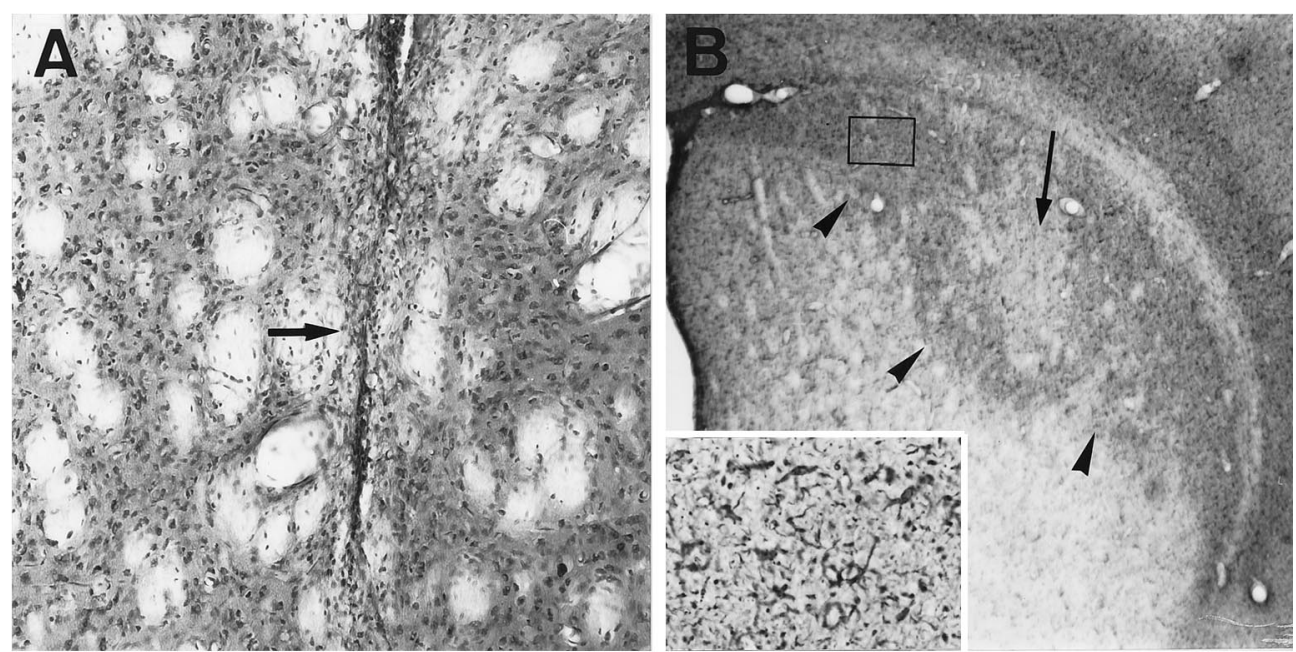

Figure 2. Biological effects of intrastriatal AdRSV.CNTF injections. $A$, Cresyl violet-stained section at $7 \mathrm{~d}$ postinjection showing no major cytopathogenicity in the vicinity of the injection site (arrow). $B$, GFAP immunohistochemistry two weeks after injection showing an immunostained area (arrowheads) widely extending beyond the injection site in the striatum (arrow). The boxed area is enlarged in the inset, which shows GFAPimmunoreactive striatal astrocytes characterized by enlarged cell body and processes. $C$, GFAP immunohistochemistry $96 \mathrm{hr}$ postinjection showing immunostained astrocytes in the injected striatum $(S)$ and in the adjacent globus pallidus $(G P)$. GFAP immunostaining is much lower on the noninjected side $(D)$. $E$, GFAP immunohistochemistry at $96 \mathrm{hr}$ postinjection showing immunostained astrocytes in the substantia nigra, pars reticulata $(S N R)$, and pars compacta $(S N C)$ on the side of the injection. GFAP immunostaining is much lower on the noninjected side $(F)$. Scale bar (at bottom right): $250 \mu \mathrm{m}$ in $A, C-F ; 400 \mu \mathrm{m}$ in $B ; 160 \mu \mathrm{m}$ in the inset.
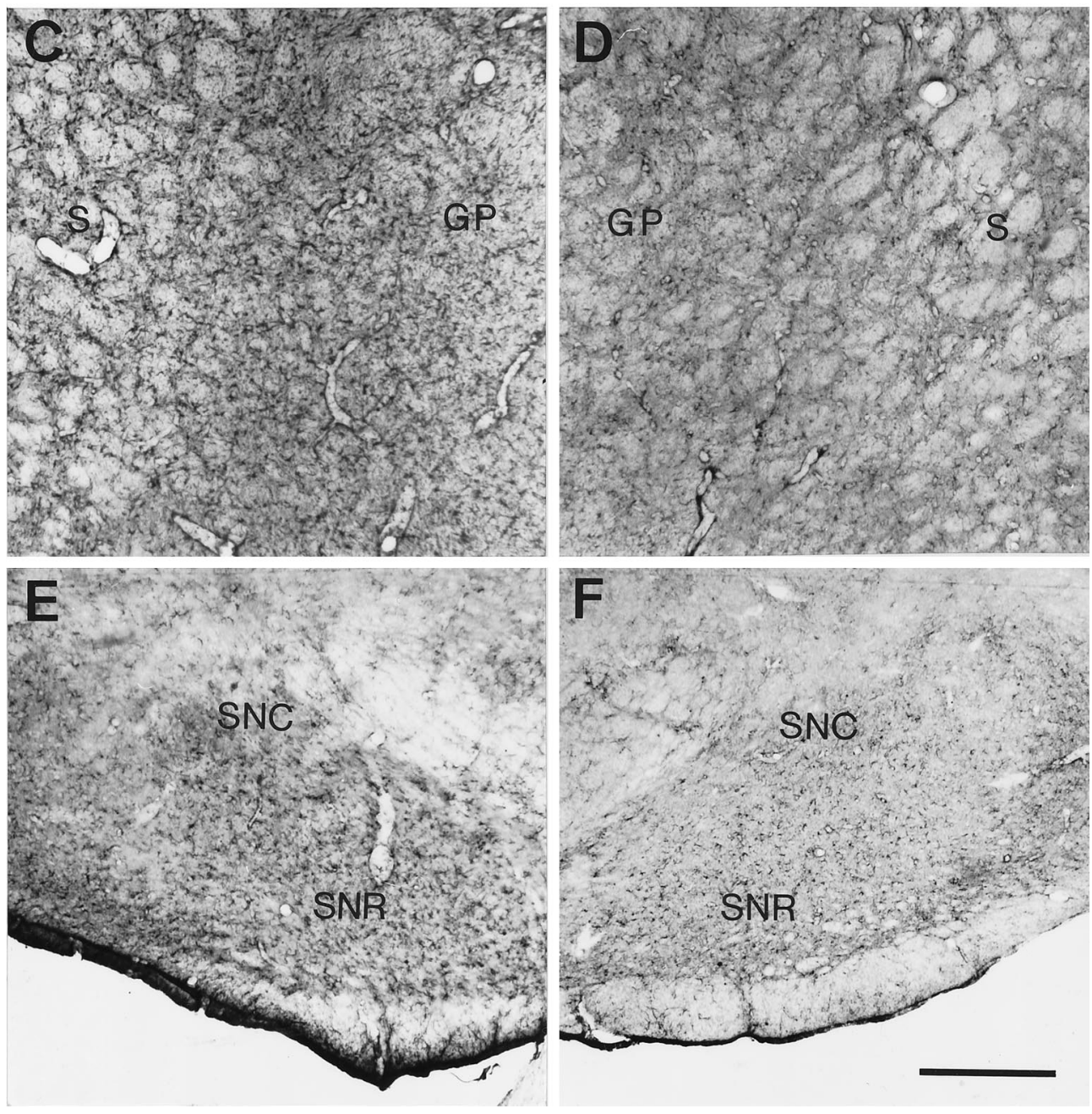

tralaminar thalamic nuclei, and the substantia nigra, both pars reticulata and pars compacta (Fig. 4C). This was not observed with AdRSV.nlslacZ injections, in which only hypertrophied astrocytes bordering the needle track (Fig. 4D) or a lesion site were immunopositive for CNTF. This type of astroglial reactivity, characterized by a restricted area containing hypertrophic GFAP-immunoreactive astrocytes and by the presence of a small number of CNTF-immunoreactive hypertrophic astrocytes at the border of a lesion, clearly was related to a lesion effect, because it also was obtained when lesions were produced by intrastriatal injection of quinolinic acid or $\mathrm{MPP}^{+}$(Fig. 4E).

When colchicine was injected intraventricularly to block axonal transport, CNTF immunoreactivity increased after injection of AdRSV.CNTF, but only in cells aligned along the needle track within a radius of $200-400 \mu \mathrm{m}$ (Fig. $4 F$ ), i.e., corresponding to the small area of dense CNTF immunoreactivity described above. No increase in CNTF immunoreactivity was seen in the surrounding striatum nor in other brain nuclei. Adjacent sections, 

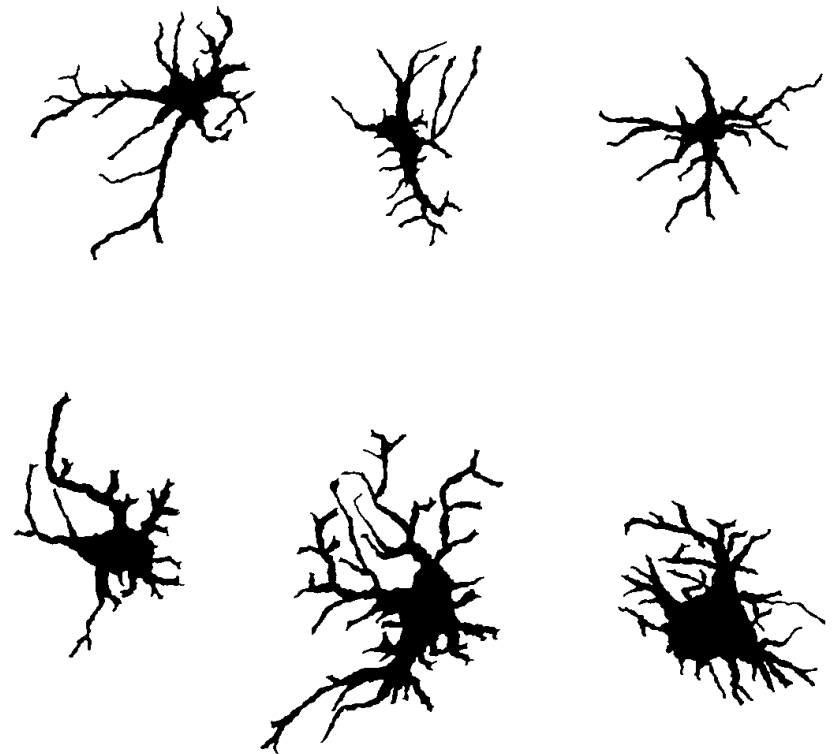

Figure 3. Camera lucida drawings of representative GFAPimmunoreactive astrocytes in the normal (noninjected) striatum (top) and in the striatal area surrounding an injection of AdRSV.CNTF (bottom). Note the hypertrophy of CNTF-treated astrocytes at the level of both their cell body and primary processes. Scale bar, $20 \mu \mathrm{m}$.

treated for GFAP immunoreactivity, showed only densely stained astrocytes in a striatal area surrounding the injection site within a radius $<1 \mathrm{~mm}$.

\section{DISCUSSION}

The present study addressed the issue of a role for CNTF in the intact adult $\mathrm{CNS}$ as a differentiating factor for astroglia. Based on a methodology that made use of in situ transduction of neural cells by recombinant adenoviral vectors, the results obtained indicate that CNTF release induced morphological and biochemical changes in astrocytes in the absence of a lesion. These changes comprised a hypertrophy of astrocytes and an increase in immunoreactivity for both GFAP and CNTF. The terms "differentiation" or "stage of differentiation" were used in this paper, rather than "reactivity" or "astrogliosis," because the latter have functional implications that were not obvious here. It is proposed that these results may reveal a role played by endogenous CNTF in the adapted response of astroglial populations to localized stimulations.

\section{Adenovirus-mediated gene transfer into the striatum elicited CNTF release in striatal afferent nuclei and projection zones}

The replication-deficient adenovirus has emerged in recent years as a vector of choice to transfer a gene of interest into the CNS, because it is able to transduce very efficiently the postmitotic neural cells (Akli et al., 1993; Bajocchi et al., 1993; Davidson et al., 1993; Le Gal La Salle et al., 1993). Although recombinant adenoviral vectors can transduce all neural cell types in culture (Caillaud et al., 1993), they seem to be particularly efficient for neurons in vivo (Lisovoski et al., 1994) (see references and discussion in Peltekian et al., 1997) after intraparenchymal administration. Therefore, it is likely that the results obtained in the present study are attributable mainly to CNTF produced and released (because of the adjunction of a signal peptide) by striatal neurons directly transduced at the injection site and neurons retrogradely transduced in afferent nuclei to the striatum.

The location of this injection site was identified by the needle track, but the volume of tissue in which cells were transduced could not be assessed directly after injection of AdRSV.CNTF, because the probe used for in situ hybridization hybridized, apparently, with transcripts of both the transgene and an endogenous gene. Three arguments plead, however, in favor of a discrete cylindrical site around the needle track of not more than a few hundred micrometers in diameter. First, this is the result obtained when an adenovirus recombinant for the lacZ marker gene was used, as already described (Akli et al., 1993; Davidson et al., 1993) (see discussion in Peltekian et al., 1997), and confirmed in the controls performed in the present study. Second, this corresponded to an area that exhibited a higher intensity of CNTF immunostaining than surrounding regions in the striatum. Third, intraventricular injection of colchicine restricted CNTF immunolabeling to a similar cylindrical region, suggesting that transport systems were involved in the labeling of other regions. As indicated in Figure 4, the region encompassing directly transduced cells most probably was, therefore, very limited. Neurons located in remote nuclei (i.e., the medial and intralaminar thalamus and the substantia nigra pars compacta) probably also expressed the CNTF transgene carried by the adenoviral vector, because retrograde transport leading to gene expression has been observed in control experiments in the same regions after injection of a vector recombinant for the lacZ gene, in agreement with previous studies (Akli et al., 1993; Ghadge et al., 1995). At least three different populations of neurons produced CNTF, therefore, under our conditions, namely striatal, thalamic, and nigral (compacta) neurons.

Because the gene construct included the NGF signal peptide, CNTF might be released not only directly in these three regions but also after anterograde axonal transport of the protein to axonal terminals in striatal projection zones (e.g., globus pallidus, entopeduncular nucleus, and substantia nigra pars reticulata) as well as in the projection zones of retrogradely transduced nigral and medial intralaminar thalamic neurons (large parts of the striatum and thalamic reticular nucleus) (Fig. 5). There was complete overlap among these theoretical sites of effect and those in which morphological and biochemical phenotypic changes of astrocytes were, indeed, observed. This overlap strongly supports the conclusion that these changes were attributable to the biological effect of the factor. The lack of inflammation and lesion in these projection zones remote from the sites of transduction concurs, in addition, with the conclusion that our results reveal an effect of CNTF in the intact neural parenchyma.

\section{Apparent low efficiency of the astroglial differentiating action of CNTF}

Taking into account only the results obtained specifically in areas of projection of transduced neurons (globus pallidus, entopeduncular nucleus, substantia nigra pars reticulata from the striatum, and reticularis thalami from the medial intralaminar thalamus) because they are the least susceptible to lesion or inflammationrelated artifacts, one major characteristic of the CNTF astroglial effect was its spatial restriction, that is, in the close vicinity of axonal terminals of transduced neurons. This is exemplified clearly by the absence of astroglial changes in the thalamic ventrobasal nucleus, which borders for several millimeters the reticu- 

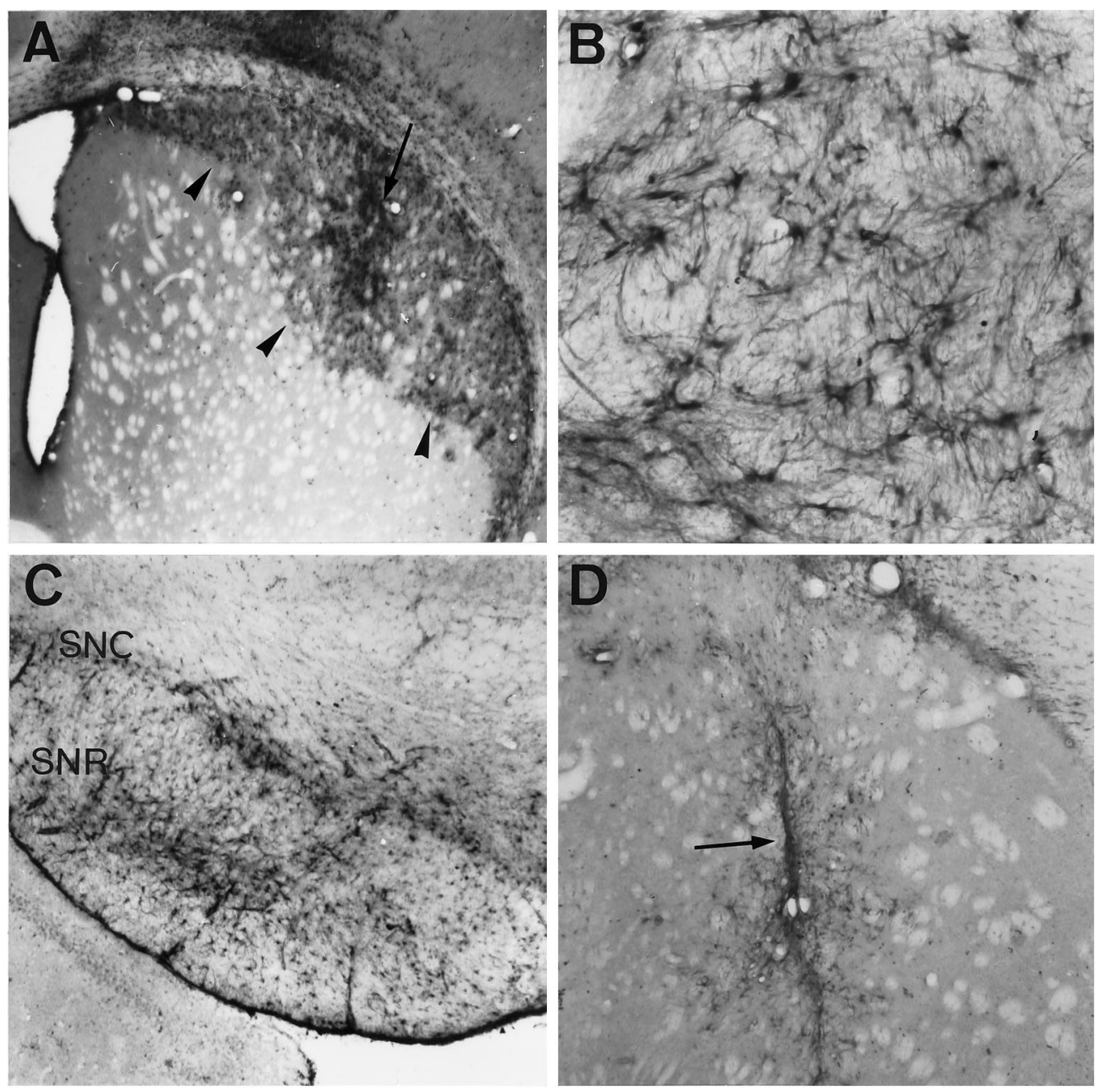

Figure 4. A, CNTF immunoreactivity 2 weeks after injection of AdRSV. CNTF into the striatum in a section adjacent to the one immunostained for GFAP in Figure $2 A$. The area surrounding the needle track is densely stained (arrow), but immunoreactive elements are present in much wider areas (arrowheads). B, High-power view of immunoreactive cells in the striatal area surrounding an injection site. $C, \mathrm{CNTF}$-immunoreactive cells in the substantia nigra pars reticulata $(S N R)$ and pars compacta $(S N C)$ on the side of the injection $4 \mathrm{~d}$ after injection of AdRSV.CNTF. D, CNTF immunoreactivity after injection of AdRSV. nlsLacZ in the striatum (arrow). E, CNTF-immunoreactive hypertrophic astrocytes at the border of a lesion $(L)$ obtained by intrastriatal injection of $\mathrm{MPP}^{+} . F, \mathrm{CNTF}$-immunoreactive cells (arrowheads) at the injection site after intraventricular injection of colchicine. Scale bar (at bottom right): $400 \mu \mathrm{m}$ in $A$; $250 \mu \mathrm{m}$ in $C, D, F ; 80 \mu \mathrm{m}$ in $B, E$.
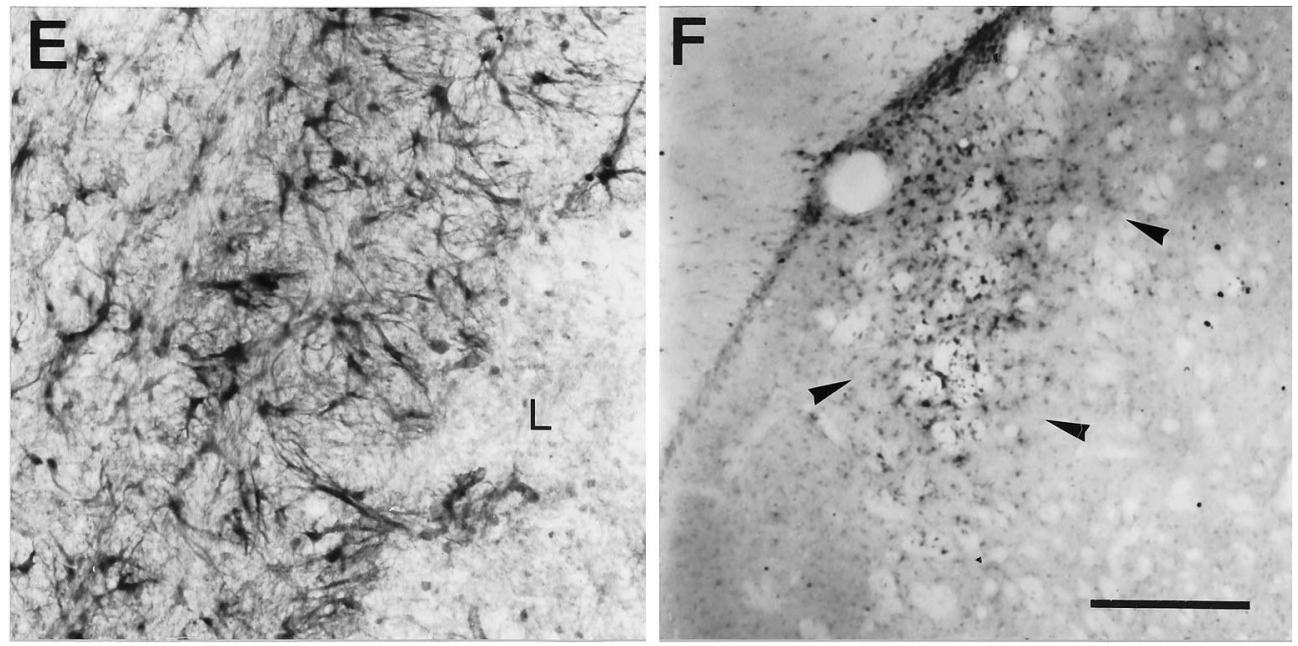

laris thalami-in which astroglial changes were visible along its entire length. Even in a single given nucleus, such as the pars reticulata of the substantia nigra, changes in astroglial phenotype seemed possible only in small subregions (e.g., Fig. 4C).

This spatial restriction could, hypothetically, result from two mechanisms: a lack of diffusion of CNTF in the parenchyma or a low efficiency of the CNTF stimulation of astroglia, which would require the factor to be particularly concentrated at the astrocytic membrane to induce phenotypic changes. It has, however, been demonstrated that CNTF exerts neuroprotective ef- fects in wide areas around an injection site (Clatterbuck et al., 1993; Hagg and Varon, 1993; Anderson et al., 1996) and even several millimeters away from an intraventricular injection (Emerich et al., 1996). This capacity of diffusion from the ventricular system is, in fact, one of the bases of an ongoing clinical trial in patients with amyotrophic lateral sclerosis (Aebischer et al., 1996a,b). The lack of intraparenchymal diff usion of CNTF is, therefore, an unlikely hypothesis. In contrast, the second hypothesis, which says that the spatial restriction of the CNTF astroglial effect relates to a limited efficiency, is supported indirectly by 


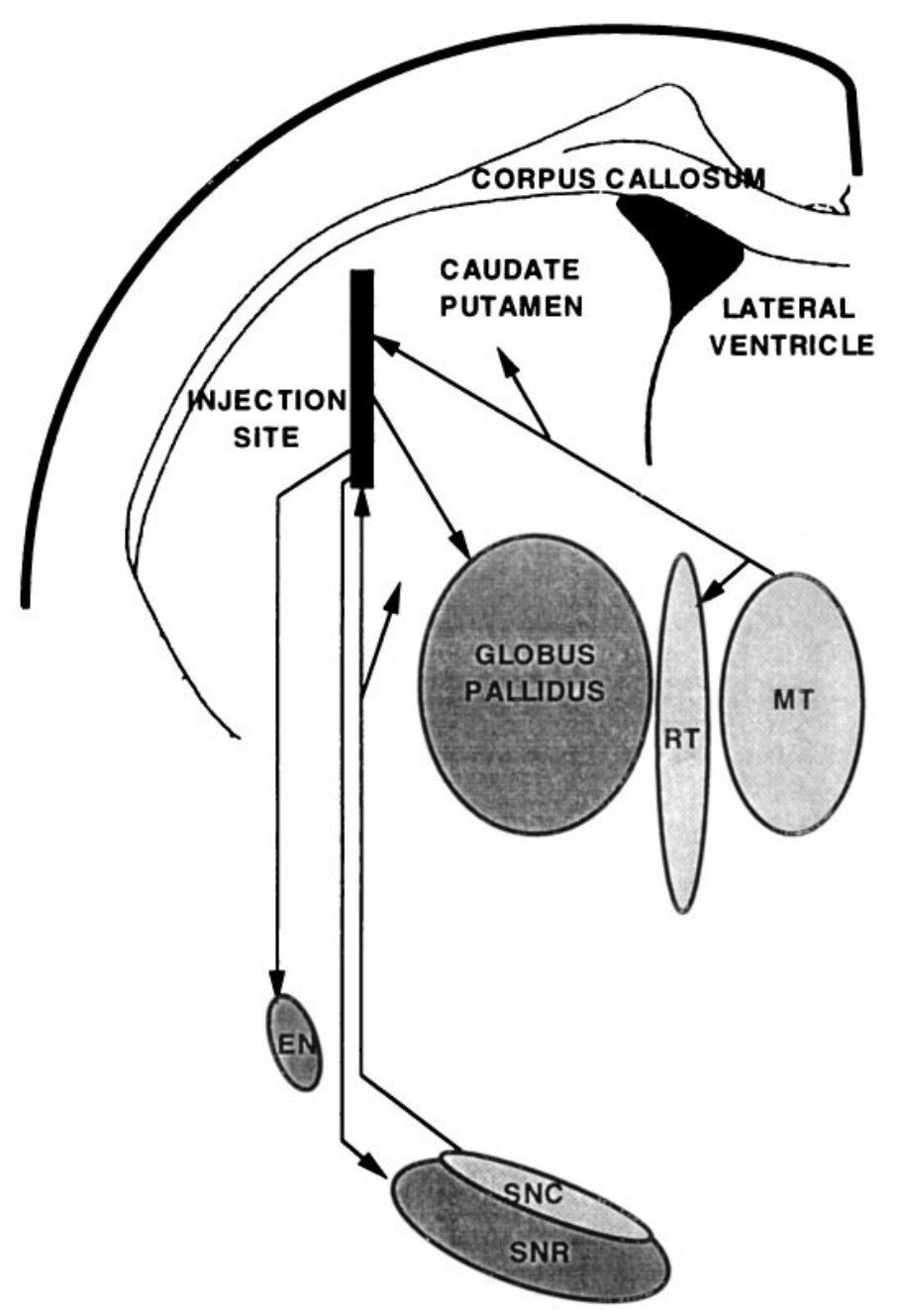

Figure 5. Scheme indicating all of the areas exhibiting phenotypic changes of astrocytes after intrastriatal injection of CNTF-recombinant adenovirus and the axonal pathways linking them to the striatum. The globus pallidus, the entopeduncular nucleus $(E N)$, and the substantia nigra pars reticulata $(S N R)$ receive axons from neurons located at the injection site. The neurons in the medial intralaminar thalamus $(M T)$ and the substantia nigra pars compacta $(S N C)$, which were retrogradely transduced, send axons to the injected striatum. The reticularis thalami nucleus $(R T)$ is not connected directly to the injected striatum, but it receives axon collaterals from neurons in the medial intralaminar thalamus.

many results. Emerich et al. (1996), for instance, have shown a major neuroprotection in the striatum in the absence of a reported glial differentiation after continuous intraventricular CNTF release by encapsulated cells at a rate $\left(15 \mathrm{ng} / 10^{6}\right.$ cells per $24 \mathrm{hr}$ ), which is in the range of that obtained by recombinant adenovirus in culture (Smith et al., 1996) and probably is an order of magnitude superior to the CNTF concentration in the present study. Reciprocally, Winter et al. (1995) and Levison et al. (1996) have shown so-called "astrogliosis," and Clatterbuck et al. (1996) have described more precisely the phenotypic alteration of astrocytes as "gemistocytic" after injections of recombinant CNTF in the vicinity of intraparenchymal injection sites in the first two studies and more widespread, but using a much higher $(1 \mu \mathrm{g})$ very concentrated $(0.2 \mu \mathrm{l})$ amount of CNTF, in the last study.

Altogether, a low-efficiency CNTF effect on astrocytes, relative to the highly efficient neuroprotective action of the factor, may help to explain why contradictory results have been obtained in experiments looking for a glial effect (Meyer and Unsicker, 1994; Kahn et al., 1995; Winter et al., 1995; Clatterbuck et al., 1996; Levison et al., 1996; Smith et al., 1996) (see references and discussion in Sendtner et al., 1994). This hypothesis adds to, but does not oppose, two other suggestions recently put forward by Smith et al. (1996), namely, an effect related to a particular stage of glial differentiation or requiring specific cell-to-cell interaction.

\section{Possible biological significance of a low-efficiency astroglial stimulating system}

The results obtained here are based on a release of CNTF deemed nonphysiological because of alteration by the addition of a signal peptide and because a neuronal source has been created, rather than the normal astroglial one (Stöckli et al., 1991; Ip et al., 1993). From the present results, one can only, therefore, extrapolate to the biological significance of a possible astroglio-astroglial signaling system suggested by our study. Within these limits it is interesting to note that CNTF release can be stimulated in astrocytes in culture by numerous factors such as IL- $1 \beta, \mathrm{TNF} \alpha$, and EGF (Kamiguchi et al., 1995); reciprocally, CNTF synthesis is inhibited by cAMP-dependent systems (Rudge et al., 1994), suggesting that, under specific physiological conditions, a CNTFbased signaling system may be finely tuned. One may speculate that the increase in synthesis of CNTF in one astrocyte, directly stimulated, may be instrumental in the tuning of the stage of differentiation of other astrocytes located in the vicinity, but not directly affected, which may then via this system participate in an adapted response of an astroglial population as a whole to the original stimulus. According to this hypothesis, CNTF could participate in normal astroglial interactions in the intact adult CNS. It remains to be understood how CNTF may participate in glial interactions with neurons, knowing that, in the intact CNS, most of the specific CNTF receptors are expressed by the latter on their cell surface (MacLennan et al., 1996).

\section{REFERENCES}

Adler R (1993) Ciliary neurotrophic factor as an injury factor. Curr Opin Neurobiol 3:785-789.

Aebischer P, Pochon NAM, Heyd B, Déglon N, Joseph JM, Zurn AD, Baetge EE, Hammang JP, Goddard M, Lysaght M, Kaplan F, Kato AC, Schluep M, Hirt L, Regli F, Porchet F, De Tribolet N (1996a) Gene therapy for amyotrophic lateral sclerosis (ALS) using a polymer encapsulated cell line engineered to secrete hCNTF. Hum Gene Ther 7:851-860.

Aebischer P, Schluep M, Déglon N, Joseph JM, Hirt L, Heyd B, Goddard M, Hammang JP, Zurn AD, Kato AC, Regli F, Baetge E (1996b) Intrathecal delivery of CNTF using encapsulated genetically modified xenogenic cells in amyotrophic lateral sclerosis patients. Nat Med 2:696-699.

Akli S, Caillaud C, Vigne E, Stratford-Perricaudet LD, Poenaru L, Perricaudet M, Kahn A, Peschanski M (1993) Transfer of a foreign gene into the brain using adenovirus vectors. Nat Genet 3:224-228.

Anderson KD, Panayatatos N, Corcoran TL, Lindsay RM, Wiegand S (1996) Ciliary neurotrophic factor protects striatal output neurons in an animal model of Huntington disease. Proc Natl Acad Sci USA 93:7346-7351.

Bajocchi G, Feldman SH, Crystal RG, Mastrangeli A (1993) Direct in vivo gene transfer to ependymal cells in the central nervous system using recombinant adenovirus vectors. Nat Genet 3:229-234.

Bloch-Gallego E, Huchet M, el M'Hamdi H, Xie FK, Tanaka H, Henderson CE (1991) Survival in vitro of motoneurons identified or purified by novel antibody-based methods is selectively enhanced by musclederived factors. Development 111:221-232.

Caillaud C, Akli S, Vigne E, Koulakoff A, Perricaudet M, Poenaru L, Kahn A, Berwald-Netter Y (1993) Adenoviral vector as a gene delivery system into cultured rat neuronal and glial cells. Eur J Neurosci 5:1287-1291.

Clatterbuck RE, Price DL, Koliatsos VE (1993) Ciliary neurotrophic 
factor prevents retrograde neuronal death in the adult central nervous system. Proc Natl Acad Sci USA 90:2222-2226.

Clatterbuck RE, Price DL, Koliatsos VE (1996) Ciliary neurotrophic factor stimulates the expression of glial fibrillary acidic protein by brain astrocytes in vivo. J Comp Neurol 369:543-551.

Davidson BL, Allen ED, Kozarsky KF, Wilson JM, Roessler BJ (1993) A model system for in vivo gene transfer into the central nervous system using an adenoviral vector. Nat Genet 3:219-223.

Emerich DF, Lindner MD, Winn SR, Chen EY, Frydel BR, Kordower JH (1996) Implants of encapsulated human CNTF-producing fibroblasts prevent behavioral deficits and striatal degeneration in a rodent model of Huntington's disease. J Neurosci 16:5168-5181.

Florkiewicz RZ, Majack RA, Buechler RD, Florkiewicz E (1995) Quantitative export of FGF-2 occurs through an alternative, energydependent, non-ER/Golgi pathway. J Cell Physiol 162:388-399.

Ghadge GD, Roos RP, Kang UJ, Wollmann R, Fishman PS, Kalynych AM, Barr E, Leiden JM (1995) CNS gene delivery by retrograde transport of recombinant replication-defective adenoviruses. Gene Ther 2:132-137.

Graham FL, Smiley J, Russell WC, Nairn R (1977) Characteristics of a human cell line transformed by DNA from human adenovirus type 5 . J Gen Virol 36:59-74.

Hagg T, Varon S (1993) Ciliary neurotrophic factor prevents degeneration of adult rat substantia nigra dopaminergic neurons. Proc Natl Acad Sci USA 90:6315-6319.

Henderson CE, Camu W, Clement M, Gouin A, Poulsen K, Karihaloo M, Rullomas M, Evans T, McMahon SB, Armanini M, Berkemeier L, Phillips H, Rosenthal A (1993) Neurotrophins promote motor neuron survival and are present in embryonic limb bud. Nature 363:266-270.

Hughes SM, Lillien LE, Raff MC, Rohrer H, Sendtner M (1988) Ciliary neurotrophic factor induces type-2 astrocytes differentiation in culture. Nature 335:70-73.

Ip N, McClain J, Barrezueta NX, Aldrich TH, Pan L, Li Y, Wiegand SJ, Friedman B, Davis S, Yancopoulos GD (1993) The alpha component of the CNTF receptor is required for signaling and defines potential CNTF targets in the adult and during development. Neuron 10:89-102.

Jaurand MC, Bernaudin JF, Renier A, Kaplan H, Bignon J (1981) Rat pleural mesothelial cells in culture. In Vitro 17:98-106.

Kahn MA, Ellison JA, Speight GJ, DeVellis J (1995) CNTF regulation of astrogliosis and the activation of microglia in the developing rat central nervous system. Brain Res 685:55-67.

Kamiguchi H, Yoshida K, Sagoh M, Sasaki H, Inaba M, Wakamoto H, Otani M, Toya S (1995) Release of ciliary neurotrophic factor from cultured astrocytes and its modulation by cytokines. Neurochem Res 20:1187-1193.

Le Gal La Salle G, Robert JJ, Bernard S, Ridoux V, Stratford-Perricaudet LD, Perricaudet M, Mallet J (1993) An adenovirus vector for gene transfer into neurons and glia in the brain. Science 259:988-990.

Levison SW, Ducceschi MH, Young GM, Wood TL (1996) Acute exposure to $\mathrm{CNTF}$ in vivo induces multiple components of reactive gliosis. Exp Neurol 141:256-268.

Lillien LE, Sendtner M, Rohrer H, Hughes SM, Raff MC (1988) Type-2 astrocytes development in rat brain cultures is initiated by a CNTF-like protein produced by type-1 astrocytes. Neuron 1:485-494.

Lisovoski F, Cadusseau J, Akli S, Caillaud C, Vigne E, Poenaru L, Stratford-Perricaudet L, Perricaudet M, Kahn A, Peschanski M (1994) In vivo transfer of a marker gene to study motoneuronal development. NeuroReport 5:1069-1072.
Louis JC, Magal E, Takayama S, Varon S (1993) CNTF protection of oligodendrocytes against natural and tumor necrosis factor-induced death. Science 259:689-692.

MacLennan AJ, Vinson EN, Marks L, McLaurin DL, Pfeifer M, Lee N (1996) Immunohistochemical localization of ciliary neurotrophic factor receptor alpha expression in the rat nervous system. J Neurosci 16:621-630.

Meyer V, Unsicker K (1994) Cell density and exogenous CNTF affect CNTF mRNA levels in glial cell cultures. NeuroReport 5:1946-1948.

Peltekian A, Parrish E, Bouchard C, Peschanski M, Lisovoski F (1997) Adenovirus-mediated gene transfer to the brain: methodological assessment. J Neurosci Methods 71:77-84.

Richardson PM (1994) Ciliary neurotrophic factor: a review. Pharmacol Ther 63:187-198.

Rubartelli A, Cozzolino F, Talio M, Sitia R (1990) A novel secretory pathway for interleukin-1 $\beta$, a protein lacking a signal sequence. EMBO J 9:1503-1510.

Rudge JS, Morrissey D, Lindsay RM, Pasnikowski EM (1994) Regulation of ciliary neurotrophic factor in cultured rat hippocampal astrocytes. Eur J Neurosci 6:218-229.

Sagot Y, Tan SA, Baetge E, Schmalbruch H, Kato AC, Aebischer P (1995) Polymer encapsulated cell lines genetically engineered to release ciliary neurotrophic factor can slow down progressive motor neuronopathy in the mouse. Eur J Neurosci 7:1313-1322.

Sendtner M, Schmalbruch H, Stöckli KA, Carroll P, Kreutzberg GW, Thoenen H (1992) Ciliary neurotrophic factor prevents degeneration of motor neurons in mouse mutant progressive motor neuronopathy. Nature 358:502-504.

Sendtner M, Carroll P, Holtmann B, Hughes RA, Thoenen H (1994) Ciliary neurotrophic factor. J Neurobiol 25:1436-1453.

Smith GM, Hale J, Pasnikowski EM, Lindsay RM, Wong V, Rudge JS (1996) Astrocytes infected with replication-defective adenovirus containing a secreted form of CNTF or NT3 show enhanced support of neuronal populations in vitro. Exp Neurol 139:156-166.

Stahl N, Yancopoulos GD (1994) The tripartite CNTF receptor complex: activation and signaling involves components shared with other cytokines. J Neurobiol 25:1454-1466.

Stöckli KA, Lottspeich F, Sendtner M, Masiakowski P, Carroll P, Gotz R, Lindholm D, Thoenen H (1989) Molecular cloning expression and regional distribution of rat ciliary neurotrophic factor. Nature 342:920-923.

Stöckli KA, Lillien LE, Naher-Noé M, Breitfeld G, Hughes RA, Raff MC, Thoenen H, Sendtner M (1991) Regional distribution, developmental changes, and cellular localization of CNTF-mRNA and protein in the rat brain. J Cell Biol 115:447-459.

Stratford-Perricaudet LD, Levrero M, Chase JF, Perricaudet M, Brian P (1990) Evaluation of the transfer and expression in mice of an enzymeencoding gene using a human adenovirus vector. Hum Gene Ther 1:241-256.

Thoenen H (1991) The changing scene of neurotrophic factors. Trends Neurosci 14:165-170.

Winter CG, Saotome Y, Levison SW, Hirsh D (1995) A role for ciliary neurotrophic factor as an inducer of reactive gliosis, the glial response to central nervous system injury. Proc Natl Acad Sci USA 92:58655869. 